\title{
Genetic and clinical characterization of 73 Pigmentary Mosaicism patients: revealing the genetic basis of clinical manifestations
}

\author{
C. Salas-Labadía ${ }^{*}$ (D) S. Gómez-Carmona ${ }^{2,3}$, R. Cruz-Alcívar ${ }^{1,4,5}$, D. Martínez-Anaya', V. Del Castillo-Ruiz ${ }^{3}$, \\ C. Durán-McKinster ${ }^{6}$, V. Ulloa-Avilés ${ }^{1}$, E. Yokoyama-Rebollar ${ }^{3}$, A. Ruiz-Herrera ${ }^{7}$, P. Navarrete-Meneses ${ }^{1}$, \\ E. Lieberman-Hernández ${ }^{3}$, A. González-Del Angel ${ }^{8}$, D. Cervantes-Barragán ${ }^{9}$, C. Villarroel-Cortés ${ }^{3}$, A. Reyes-León ${ }^{1}$, \\ D. Suárez-Pérez ${ }^{3}$, A. Pedraza-Meléndez ${ }^{1,10}$, A. González-Orsuna ${ }^{1}$ and P. Pérez-Vera ${ }^{1 *}$
}

\begin{abstract}
Background: Pigmentary mosaicism constitutes a heterogeneous group of skin pigmentation alterations associated with multisystem involvement. The aim of this study was to establish a complete cytogenetic and molecular characterization of PM patients, emphasizing on searching for possible low chromosomal mosaicism and on establishing an accurate genotype-phenotype correlation.

Results: A total of 73 patients were included (3 months to 18 years of age), $52 \%$ male and $48 \%$ female. Observed in 69 (95\%) patients, the most frequent pattern of pigmentation was fine and whorled BL, which was associated with disseminated skin extent in 41 (59\%) patients. Central nervous system (84\%) alterations were the most frequent observed in the group of patients, followed by the musculoskeletal (53\%) and ophthalmologic (27\%) alterations. Considering the pattern of pigmentation, no significant differences in association with skin extent or extracutaneous manifestations were detected. Following a strict cytogenetic analysis strategy, screening metaphases from three different tissues (peripheral blood, hyperpigmented and hypopigmented skin) we found that 23/73 patients had chromosomal abnormalities classified as follows: 1) Mosaic with 2 or more different cell lines with structural alterations $n=19 ; 2$ ) Polyploidy (mosaic) $n=1$ and 3) Alterations in all cells in three different tissues $n=3$. SNP array, array CGH and FISH were useful for the complete characterization of the chromosomal aberrations, for the detection of microdeletions in patients with normal karyotype but with strong clinical suspicious of chromosomal alteration, and for a better establishment of genotype-phenotype correlation. In 2 patients we found genes associated with some of the extracutaneous manifestations (SHH, MNX1, PPP2R2C).

Conclusions: This group of 73 patients finely described is the largest series of patients with pigmentary mosaicism reported worldwide. As we showed in this study, the followed analysis strategy allowed the detection of cytogenetic and molecular abnormalities, and made possible the establishment of genotype-phenotype associations in some patients. An important limitation of our study was the analysis of fibroblasts cultures instead of melanocytes and keratinocytes. In some cases the direct molecular DNA analysis of skin biopsy could be another choice.
\end{abstract}

Keywords: Pigmentary mosaicism, Cytogenetic and molecular characterization, Genotype-phenotype correlation

\footnotetext{
* Correspondence: consusa@hotmail.com; pperezvera@yahoo.com

'Laboratorio de Genética y Cáncer, Departamento de Genética Humana,

Instituto Nacional de Pediatría, 04530 Ciudad de México, Mexico

Full list of author information is available at the end of the article
}

(c) The Author(s). 2019 Open Access This article is distributed under the terms of the Creative Commons Attribution 4.0 International License (http://creativecommons.org/licenses/by/4.0/), which permits unrestricted use, distribution, and

reproduction in any medium, provided you give appropriate credit to the original author(s) and the source, provide a link to the Creative Commons license, and indicate if changes were made. The Creative Commons Public Domain Dedication waiver (http://creativecommons.org/publicdomain/zero/1.0/) applies to the data made available in this article, unless otherwise stated. 


\section{Background}

Pigmentary mosaicism (PM) of the hypomelanosis of Ito type (IH) (OMIM\#300337) or of the linear and whorled nevoid hypermelanosis type (LWNH) (OMIM\#614323) constitutes a heterogeneous group of skin pigmentation disorders characterized by the presence of hypopigmented and hyperpigmented macules, which follow patterns of cutaneous mosaicism as evidence of migration routes of melanocytes and keratinocytes during embryogenesis, known as Blaschko lines (BL). The cutaneous mosaicism can occur in 6 different archetypical patterns including the fine and whorled and the broad BL pattern, and depending on the part of the body where it occurs (cell type), they are distributed differently (Fig. 1) [13]. It is important to note the existence of less-well defined patterns as the Pallister-Killian pattern, the mesotropic facial pattern and a third described as cutis tricolor like $[4,5]$.

In IH or LWNH PM type patients, the different skin pigmentation patterns may appear as a unique manifestation or in association with extracutaneous manifestations, mainly of the central nervous system (CNS), so it has been characterized as a neurocutaneous disorder [6-9]. Multisystem involvement has been observed in $30-90 \%$ of PM patients, and the most common findings are intellectual disability (ID) and seizures in 40-60\% of PM patients. Ocular abnormalities, musculoskeletal deformities (M-S) and dysmorphic facial features (DFF) are other frequent findings $[8,10-14]$.

The presence of cytogenetic alterations as the pathogenic basis of PM has been key to explain the wide variability of clinical manifestations in these patients. Several chromosomal aberrations (polyploidy, aneuploidies, marker chromosomes, rings, deletions and translocations) have been observed in $30-60 \%$ of PM cases when both leukocytes and cultured fibroblasts are evaluated in the same patient, and in more than $80 \%$ of the cases chromosomal abnormalities are present in mosaic state [3,12, 14-17]. It is assumed that the presence of differential skin pigmentation could be related with two distinct genotypes in each type of skin [2]. Different types of genetic pathogenic variants have also been reported, such as microdeletions and mutations in genes associated with skin pigmentation and the presence of other associated abnormalities [12, 16-19]. The high proportion of genetic mosaicism observed in PM patients, together with the great variability at clinical and genetic levels, highlights the importance to establish a strategy that increases the probability of finding genetic abnormalities even in mosaic state, for a better characterization of this entity. The aim of this study is to achieve a complete cytogenetic and molecular characterization on the largest group of patients with PM, emphasizing on searching for possible low chromosomal mosaicism and on establishing an accurate genotypephenotype correlation.

\section{Subjects and methods}

We included 73 pediatric patients with PM with or without other systemic anomalies referred from four different hospitals in Mexico from 2006 to 2018, and diagnosed by Genetics and Dermatology departments. Information on sex, age, dermatological findings, such as a) type of pigmentation: hypopigmentation / Light skin (LS), hyperpigmentation / Dark skin (DS)

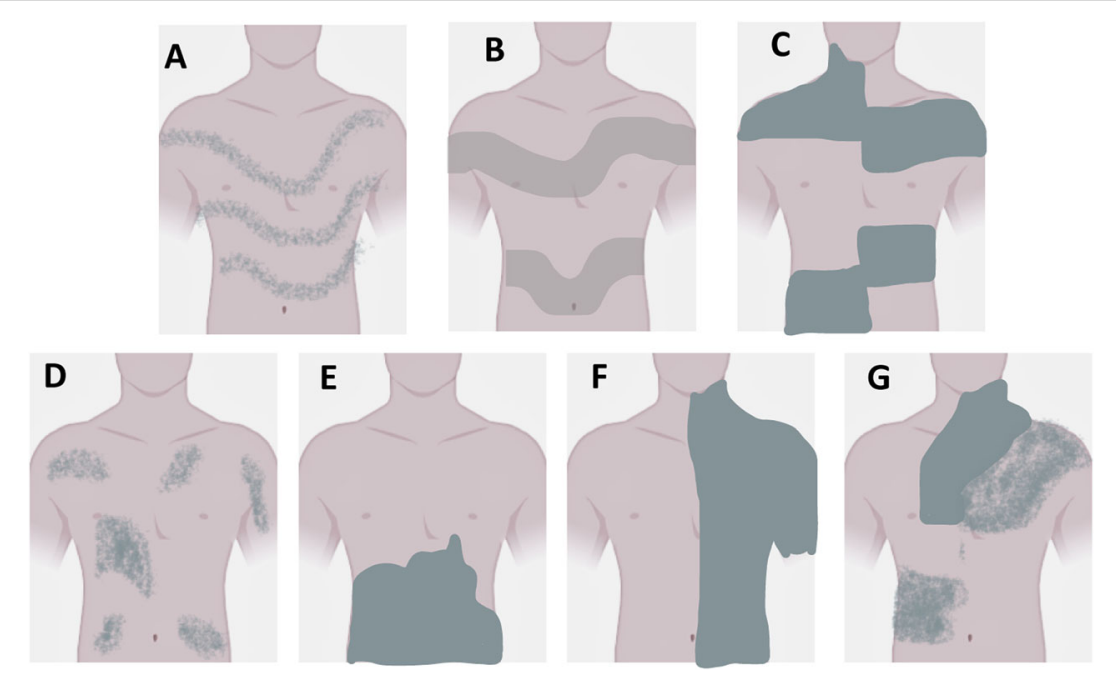

Fig. 1 Pigmentary Mosaicism Arquetypes. a) Narrow bands Blaschko lines; b) Broad bands Blaschko lines; c) Checkerboard pattern; d) Phylloid pattern; e) Patchy pattern without midline separation; f) Lateralization pattern and g) Sash-like pattern 
or both; b) pigmentation pattern: fine and whorled or broad BL and skin extent of dermatosis, as well as precise data associated with extracutaneous manifestations, were obtained for each patient. It worthwhile to highlight that all of the extracutaneous manifestations were analyzed by medical specialists depending on the system affected (e.g. neurologist for CNS alterations). This study was approved by Research Ethics committee with National Commission of Bioethics registration number "CONBIOETICA-09-CEI-025-20,161,215" of Instituto Nacional de Pediatría. Signed informed consent forms were obtained according to the recommendations of the Helsinki Declaration.

As a standardized protocol, all PM patients with pigmentary abnormalities associated or not with extracutaneous manifestations were analyzed as follows: 1) Cytogenetic analysis in peripheral blood lymphocytes (PB) and in fibroblasts cultures obtained from LS and DS following standard methods. G-banded metaphases were interpreted according to the International System for Human Cytogenetic Nomenclature 2016 [20]. A total of 50 GTG-metaphases were analyzed per tissue following a strict criteria analysis. 2) Molecular analysis with SNP array or array CGH (aCGH) and/or fluorescence in situ hybridization (FISH) was performed only in patients in whom a better characterization of chromosomal abnormalities (CA) was needed. 3) This analysis also included some patients with normal karyotype, but strong clinical suspicion (ID, DFF, PM and alterations in other involved systems) of having a chromosomal alteration below the detection level of classical cytogenetics. DNA for aCGH was isolated from PB, LS and DS using the specific Qiagen Kit according to the manufacturer's instructions. aCGH 60,100, 180, $400 \mathrm{k}$ and $750 \mathrm{k}$ was carried out using Agilent Technologies (Santa Clara, CA), which contains between 60,000, and 750,000 probes, distributed between coding and non-coding human genome sequences (hg18, hg19 UCSC). SNP array genotyping was carried out using the Illumina BeadStation (Human Hap550 BeadChip (V3)). Loss of genomic regions was determined by decreases in the $\log \mathrm{R}$ ratio. Mosaic proportions were estimated by $\mathrm{B}$ allele frequencies (BAF) [21, 22].

At the clinical level and for later comparison purposes, the body regions involved in the pigmentation changes were divided in four segments: head, trunk and upper and lower limbs. Localized dermatosis was considered when only one segment was involved, and disseminated dermatosis when 2-3 segments were involved.

Pigmentation pattern, pigmentation type frequencies, and its association with skin extent dermatosis and extracutaneous manifestations were evaluated by Fisher exact test (SPSS 20.0). Presence or absence of chromosomal abnormalities, were associated with the distribution of pigmentation pattern and extracutaneous manifestations. $P$-values less than 0.05 were considered significant.

\section{Results \\ Study population}

A total of 73 patients with PM were included, $52 \%$ were male and $48 \%$ were female. Age at the time of diagnosis ranged from 3 months to 18 years. Hypopigmentation was observed in $14(19 \%)$ patients, hyperpigmentation in 31 (43\%) and combined patterns in 28 (38\%). The more frequent patterns of pigmentation were fine and whorled $\mathrm{BL}$ observed in 69 (95\%) patients, followed by broad BL pattern in $4(5 \%)$ patients (Fig. 2). The most frequently observed dermatosis was the disseminated, which was detected in 43 patients (59\%), followed by the localized, observed in 30 patients $(41 \%)$. The fine and whorled BL pattern associated with disseminated skin extent was the most frequently detected dermatosis, identified in 41 patients (59\%). The other $28(41 \%)$ patients presented a localized pattern (Fig. 2).Two patients showed a localized and two a disseminated pattern associated with the broad BL pattern. No significant difference was detected between different $\mathrm{BL}$ pattern and skin extent $(p=0.5)$. Representative photographs of patient with hyperpigmented Broad BL pattern and patient with hypopigmented fine and whorled BL pattern in trunk are included (Fig. 3).

\section{Extracutaneous manifestations}

As reported in the literature, the CNS was the most frequently involved system in the group of patients. A total of 61/73 (84\%) patients had CNS alterations including: ID, seizures, hypotonia, microcephaly, and/or abnormal EEG (epileptiform discharges: seizure activity), and MRI (focal cortical dysplasia associated alterations: heterotopia, lissencephaly and polymicrogyria). Regarding the pattern of pigmentation, 58/61 (95\%) patients with fine and whorled BL and 3/61 (5\%) with broad BL had CNS manifestations ( $p=$ 0.48) (Fig. 4). The second system most frequently involved in 39/73 patients (53\%) was the musculoskeletal system (M-S), and the hemihypertrophy was the most representative manifestation, followed by scoliosis, digital alterations and hip dysplasia. Among these 39 patients with musculoskeletal alterations, $36(92 \%)$ presented fine and whorled BL pattern and $3(8 \%)$ showed broad BL $(p=0.36)$ (Fig. 4). The third most frequently involved system was the ocular system in 20/73 patients (27\%). In this case ocular manifestations such as microphthalmia, strabismus, ptosis and cataracts were the most representative. Of the 20 patients with ocular abnormalities, 19 (95\%) presented fine and 1 (5\%) broad BL pattern (Fig. 4). Considering the pattern of pigmentation, no significant difference in association with ophthalmologic manifestations was detected $(p=0.69)$. Finally, low weight, short and tall stature, endocrine manifestations such obesity and precocious puberty, DFF, hearing 

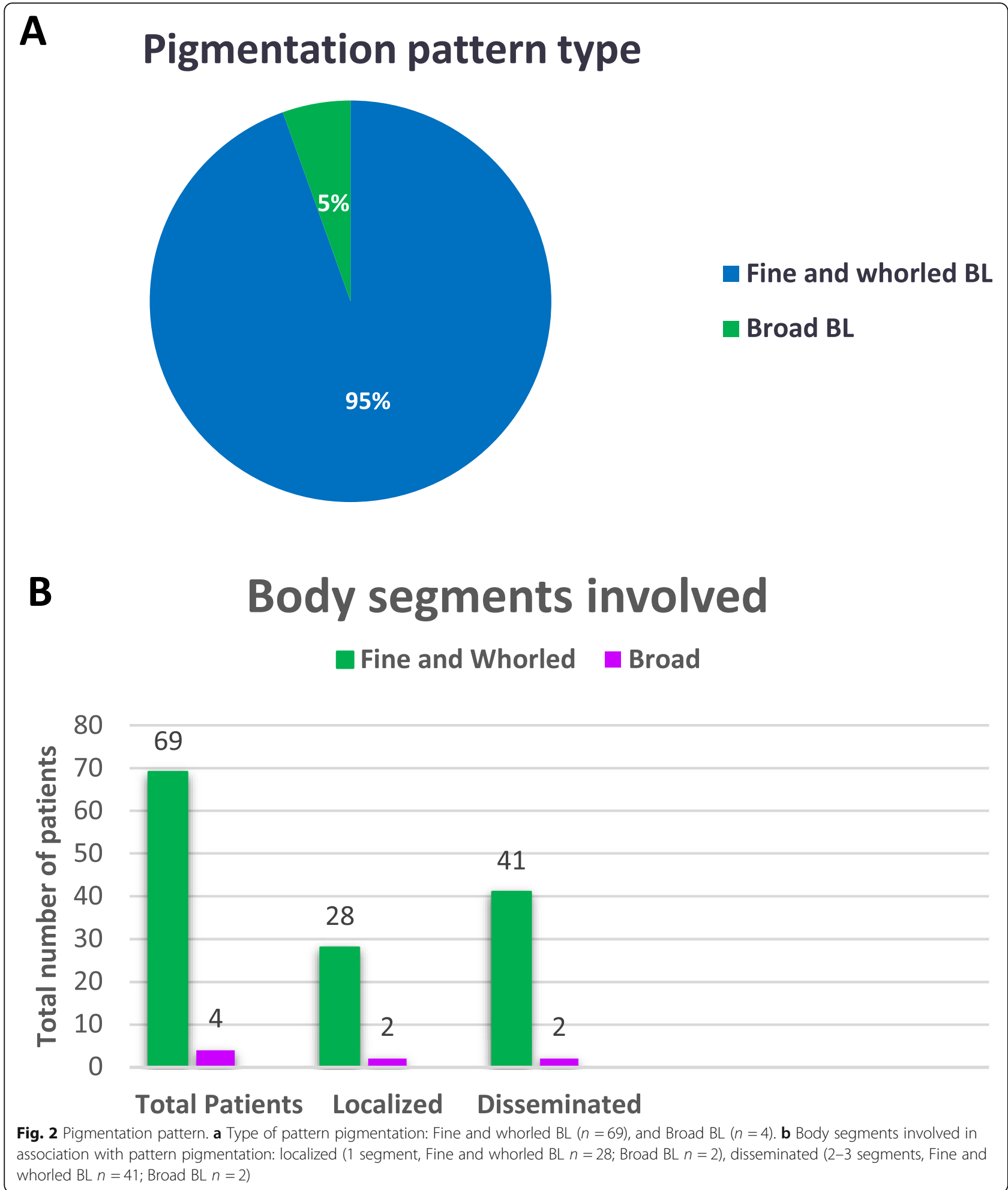

loss and involvement of cardiac, genitourinary, and digestive systems were also detected. Only 5/73 patients (7\%) did not show any extracutaneous manifestation. Importantly, 28/68 (41\%), 35/68 (52\%) and 5/68 (7\%) of patients with extracutaneous manifestations had abnormalities involving $1-2,3-5$, and more than 6 different systems, respectively. We observed statistically significant differences between groups, accordingly to the presence of other clinical 


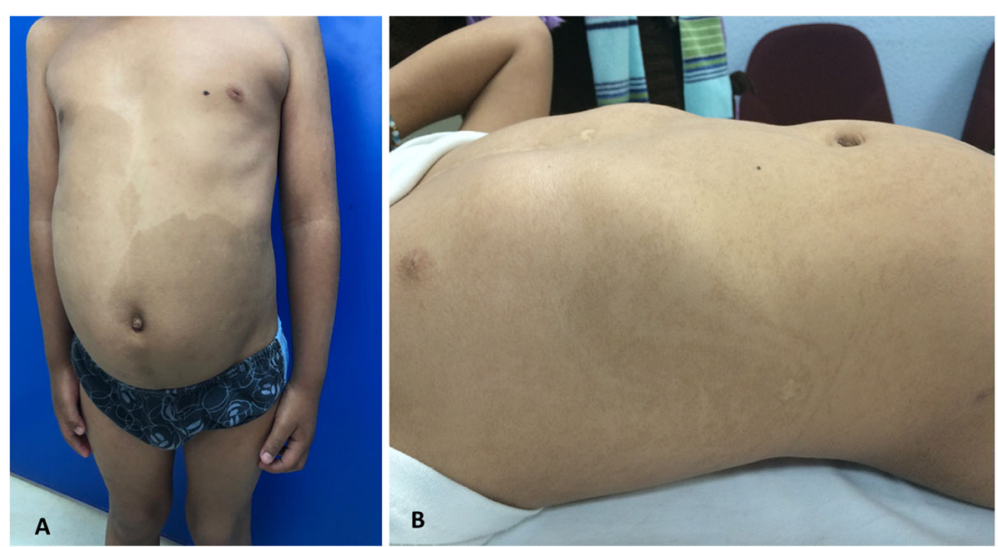

Fig. 3 a Patient with hyperpigmented Broad BL pattern; b Patient with hypopigmented fine and whorled BL pattern in trunk

manifestations in one or more systems affected in association with PM $(p<0.001)$.

\section{Cytogenetic analysis}

Cytogenetic analysis on 50 metaphases for each tissue was obtained. The analysis of the three different tissues was achieved for most patients (59/73, 81\%). For the remaining patients at least two different tissues were analyzed, both skins without PB in 12/73 (16\%) patients, and PB and LS or DS in 2/73 (3\%) patients.

The cytogenetic analysis showed abnormal karyotypes in 23/73 (31\%) patients. The frequency of patients with mosaic chromosomal abnormalities in three, two or only one tissue was 45,35 and $20 \%$, respectively. Only 3 patients had non-mosaic chromosomal abnormalities (Table 1). Polyploidy in mosaic was observed in one patient (Table 1). The chromosomes involved in the abnormalities were $1,4,7,8,12,13,14,15,16,18,22$, X, for both numerical and structural rearrangements. Chromosomes 12 and 22 presented numerical and structural rearrangements in 4 patients each (Fig. 5). The detailed descriptions of the abnormal karyotypes detected are listed in Additional file 1.

\section{Molecular analysis}

The SNP array analysis or aCGH 60, 100, 180 and $400 \mathrm{k}$ as well as FISH analysis with different probes were applied in different situations. In a subgroup of patients: PM2, PM25, PM30, PM39, PM46, PM53, PM61 and PM65, these tools were useful for detecting abnormal clones, and to complete the characterization of the chromosomal aberrations found by classical cytogenetics (See additional file 1). In another subgroup of patients with normal karyotype, but altered phenotype with ID, DFF and PM, besides the involvement of alterations in other systems, the molecular analysis by SNP array and aCGH 60 and $750 \mathrm{k}$ resulted normal (6/7 patients (PM20, PM32, PM38, PM45, PM54 and PM77)). Only one patient (PM35) with normal karyotype showed a pathogenic $0.6 \mathrm{Mb}$ deletion (16p11.2) containing more

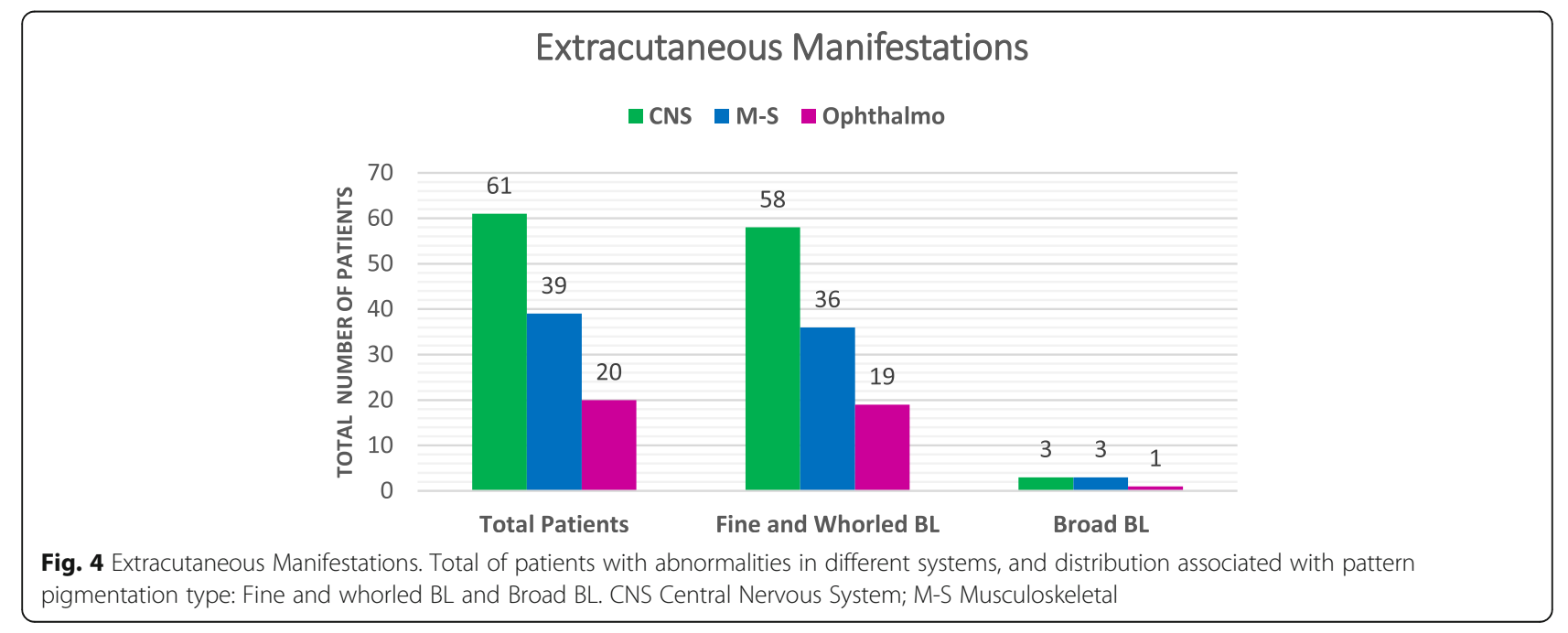


Table 1 Cytogenetic findings

Total of Patients with chromosomal alterations

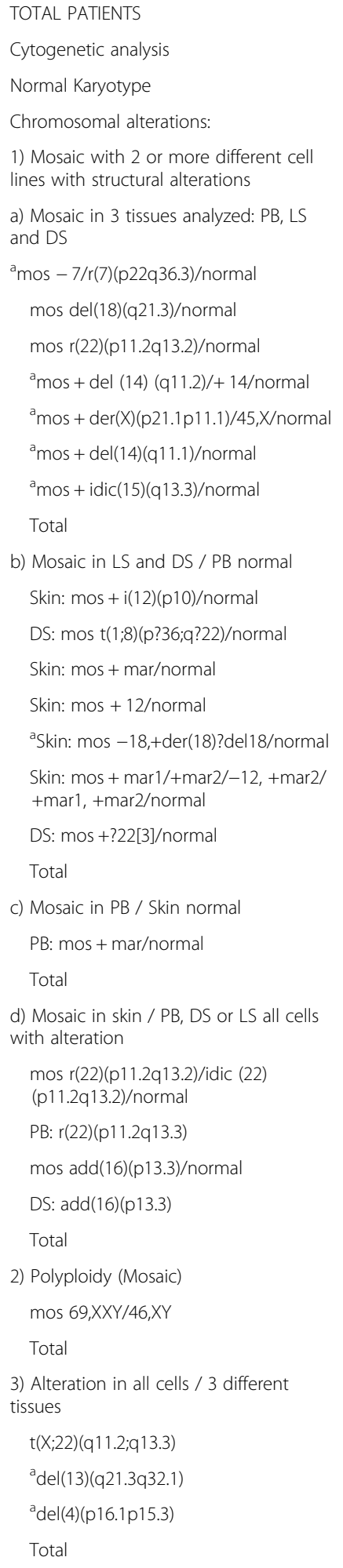

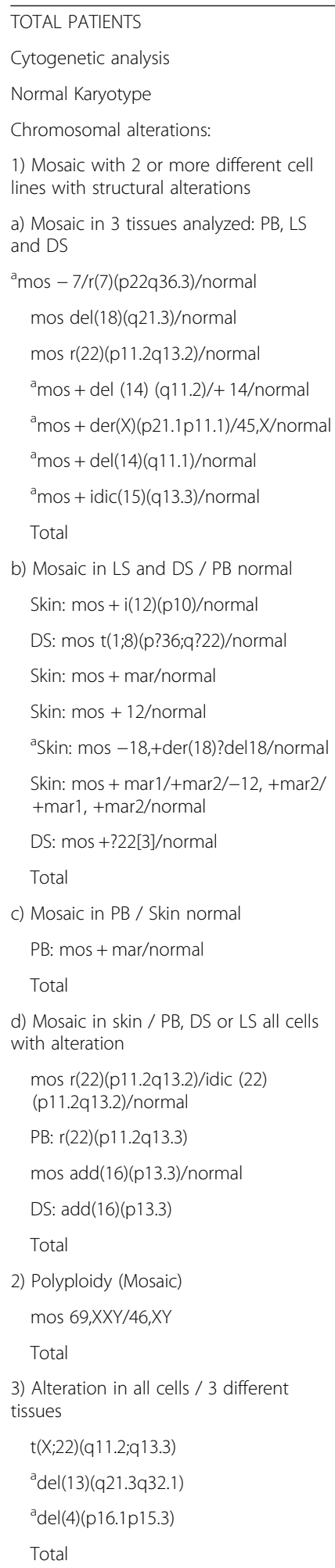

PB Peripheral Blood, LS Light Skin (hypopigmented), DS Dark Skin (hyperpigmented)

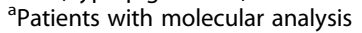




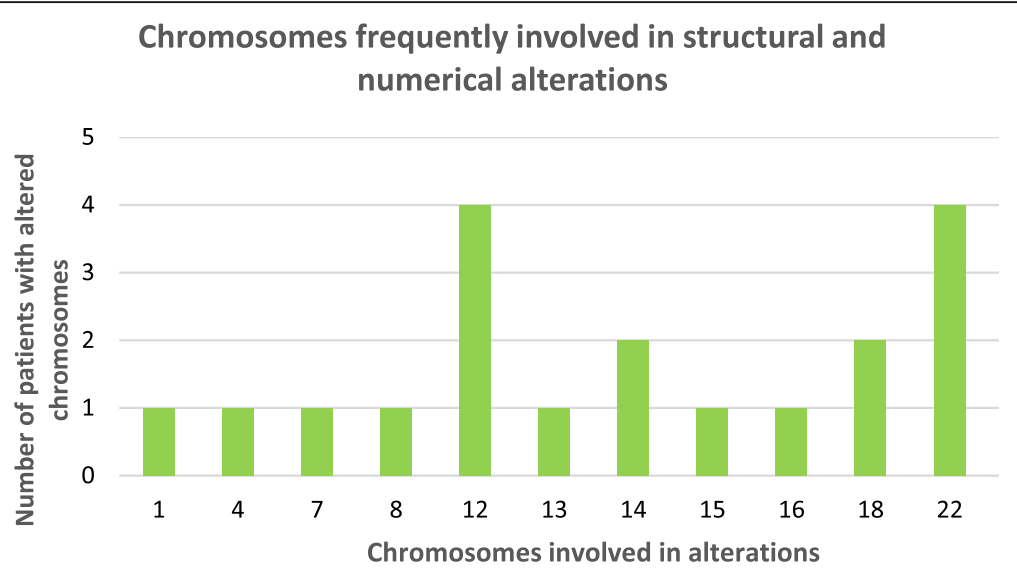

Fig. 5 Chromosomes involved in alterations. Total of structural and numerical chromosomal abnormalities for each chromosome

associated with some of the clinical manifestations of the patient (Table 2) [21].

2) 2) Cytogenetic analysis identified three cell lines in different proportions in patient PM25: One with supernumerary marker chromosome, another with trisomy 14, and a normal cell line. aCGH $180 \mathrm{k}$ confirmed the cytogenetic marker chromosome as $\operatorname{del}(14)(\mathrm{q} 11.2)$. Considering the negative results of phenotype genes association with marker chromosome and maternal UPD analysis of previous study, the phenotype of the reported patient apparently correlate with mosaic trisomy 14 (Table 2) [23].

3) The initial cytogenetic analysis of patient PM30 showed a mosaic karyotype including monosomy $\mathrm{X}$ and a supernumerary chromosome of unknown origin. FISH analysis with the $\alpha$ satellite $\mathrm{X}$ probe confirmed that the marker was a derivative $\mathrm{X}$ chromosome. The SNP array further confirmed the mosaic karyotype with a der $(\mathrm{X})$ chromosome duplicated at Xp21.1p11.1 region (Table 2). The patient's phenotype could be classified as a variant of Turner syndrome because of the partial functional disomy of the X chromosome. As reported in the literature, other patients with this functional disomy have ID and DFF (Table 2) [24].

4) The cytogenetic analysis of patient PM53 showed an interstitial del(4)(p16.1p15.3) in PB, LS and DS in all cells analyzed. aCGH100k confirmed the cytogenetic alteration as del(4)(p16.1p15.3). This deletion encompasses $7.5 \mathrm{Mb}$ outside of the WolffHirschhorn locus, and involves 30 genes. In this patient loss of the PPP2R2C gene was associated with the ID. Also, a $0.81 \mathrm{Mb}$ duplication in chromosome 8 (not associated with phenotype) was detected. (Table 2 and Fig. 6) [25].

\section{Discussion}

To date, this group of 73 patients constitutes the largest clinical and cytogenetically finely described study of cases with PM of the IH type or LWNH type, that were selected consecutively for 13 years. The pigmentary abnormalities were the main inclusion criterion, associated or not with extracutaneous manifestations.

PM is an entity mainly characterized by skin pigmentary alterations, and in this group of patients, the hyperpigmentation in fine and whorled BL pattern was the most frequently observed (49\%). In contrast, in 5 previous reports the hypopigmentation was the most frequent type of pigmentation in PM (ranging 50-100\%) [1, 3, 6, 26, 27]. Only one previous report identified hyperpigmentation as the most frequently group (77\%) [7]. It is important to notice that the combined pattern (hypo/hyperpigmentation) was the group with the lowest frequency of presentation in almost all previous studies. However, in our group the combined pigmentation pattern was as frequent as the hyperpigmentation subgroup.

Our study revealed a total of 68 (93\%) patients with extracutaneous manifestations. CNS was the most frequently involved system, followed by M-S and ophthalmologic systems. At CNS level, ID and seizures were the most common findings, as most studies have previously shown [3]. In the M-S system the asymmetric overgrowth was the most representative manifestation, observed in $11 / 73$ (15\%) patients. It is an important finding considering that in 5 previous studies, the combination of PM with asymmetric overgrowth was reported in 6/6(100\%), 8/114 (7\%), 4/34 (12\%), 4/19 (21\%) and 12/76 (16\%) patients [1, 2831]. Thus, taking together with our results, it can be appreciated that the association of PM with asymmetric overgrowth is not uncommon. Other studies showed the ophthalmologic system as the third most 
Table 2 Genotype-Phenotype correlation

\begin{tabular}{|c|c|c|c|c|c|}
\hline $\begin{array}{l}\text { Patient } \\
\text { Code }\end{array}$ & PM Pattern & $\begin{array}{l}\text { Extracutaneous } \\
\text { Manifestations }\end{array}$ & $\begin{array}{l}\text { Cytogenetic } \\
\text { Analysis }\end{array}$ & Molecular Analysis & $\begin{array}{l}\text { Association with clinical } \\
\text { manifestations }\end{array}$ \\
\hline${ }^{\mathrm{a} P M 2}$ & $\begin{array}{l}\text { Broad BL with } \\
\text { disseminated hypo } \\
\text { and } \\
\text { hyperpigmentation in } \\
\text { face, dorsum and } \\
\text { limbs }\end{array}$ & $\begin{array}{l}\text { ID, ptosis, sacral defects, } \\
\text { scoliosis, hypoplastic } \\
\text { genitalia, small testes } \\
\text { and low weight and } \\
\text { length }\end{array}$ & $\begin{array}{l}\text { PB: mos 46, XY, } \\
\text { r(7) (p22q36.3) } \\
{[45] / 45, X Y,-7[6] /} \\
46, X Y, \\
\text { dup(7)(p22q36.3) } \\
\text { [2] } \\
\text { LS: mos 45, XY, }-7 \\
\text { [23]/46, XY, r(7) } \\
\text { (p22q36) [17] } \\
\text { DS: mos 45, XY, -7 } \\
\text { [26] } \\
\text { /46, XY, r(7) } \\
\text { (p22q36) }[29]\end{array}$ & $\begin{array}{l}\text { 1. arr 7p22.3(113,336-954, } \\
\text { 145)×1,7q36.1q36.3 } \\
(151306863-158,812,247) \\
\times 1 \text {, (Human Genome Build, } \\
\text { hg18). } \\
\text { 2. FISH analysis with } \\
\text { subtelomeric probe for } \\
\text { chromosome 7: ish } \\
\text { r(7)(p22q36.3) } \\
\text { (VIJyRM2185-,VYJyRM2000-) }\end{array}$ & $\begin{array}{l}\text { 1) } 0.8 \mathrm{Mb} \text { deletion in } 7 \mathrm{p} 22.3 \\
\text { including } 8 \text { genes associated with } \\
\text { urogenital anomalies } \\
\text { 2) } 7.5 \mathrm{Mb} \text { deletion in } 7 \mathrm{q} 36.1: 50 \\
\text { RefSeq genes. Phenotype related: } \\
\text { a) } S H H \text {, eye anomalies (ptosis in } \\
\text { present case) } \\
\text { b) MNX1, sacral defects (e.g. } \\
\text { Currarino Syndrome: partial fusion } \\
\text { S2-S5 vertebrae) (21) }\end{array}$ \\
\hline${ }^{\mathrm{a} P M} 25$ & $\begin{array}{l}\text { Fine and whorled } B L \\
\text { with disseminated } \\
\text { hypo and } \\
\text { hyperpigmentation in } \\
\text { dorsum and limbs }\end{array}$ & $\begin{array}{l}\text { ID, DFF, scoliosis, hip } \\
\text { dysplasia, and low } \\
\text { weight }\end{array}$ & $\begin{array}{l}\text { PB: } \operatorname{mos} 47, X X \\
+ \text { mar }[45] / 47, X X \\
+14[10] / 46, X X \\
\text { [45] } \\
\text { LS: } \operatorname{mos} 47, X X \\
+ \text { mar [7]/46,XX [8] } \\
\text { DS: } \operatorname{mos} 47, X X \\
+\operatorname{mar}[12] / 46, X X \\
\text { [14] }\end{array}$ & $\begin{array}{l}\text { 1. arr 14q11.1q11.2(18,127,052- } \\
\text { 19,927,052)×2 3, (UCSC, h18) } \\
\text { 2. FISH with DNA BAC probes } \\
\text { for } 14 q 11.2 \text { spectrum green } \\
\text { and } 14 q 32.33 \text { spectrum } \\
\text { Final result: PB: mos } 47, X X, \\
+ \text { del(14)(q11.2)[45]/ } \\
47, X X,+14[10] / 46, X X[45]\end{array}$ & $\begin{array}{l}\text { Phenotype associated with } \\
\text { mosaic trisomy } 14(23)\end{array}$ \\
\hline PM30 & $\begin{array}{l}\text { Fine and whorled } B L \\
\text { with hypo and } \\
\text { hyperpigmentation in } \\
\text { dorsum and inferior } \\
\text { limbs }\end{array}$ & $\begin{array}{l}\text { Severe ID, seizures, } \\
\text { hypotonia and DFF. }\end{array}$ & $\begin{array}{l}\text { PB: } \operatorname{mos} 47, X X \\
+ \text { mar }[28] / 45, X[6] \\
\text { / 46, XX [16] } \\
\text { LS: } \operatorname{mos} 45, X[35] / \\
47, X X,+\operatorname{mar}[2] / \\
46, X X[6] \\
\text { DS: mos 45,X [20] } \\
\text { / 47, XX,+mar [3]/ } \\
46, X X[13]\end{array}$ & $\begin{array}{l}\text { 1. arr Xp22.33q28(60,814-155, } \\
\text { 254,881)× 1[ 30\%], } \\
\text { Xp21.1p11.1(36,025,401-58,483, } \\
\text { 247)×3 [ 55\%] (Human } \\
\text { Genome Build 37, hg19) } \\
\text { 2. FISH with a-satellite X probe } \\
\text { (AbbotMolecular/Nysis) and } \\
\text { locus specific probe (p11.22- } \\
\text { p11.23) (Agilent Tech, SureFISH) } \\
\text { positive. } \\
\text { Final result: PB: mos 47, XX, } \\
+ \text { der(X)(p21.1p11.1) [28]/45,X [6] } \\
\text { / 46, XX [16] }\end{array}$ & $\begin{array}{l}\text { Variant of Turner syndrome, } \\
\text { severe phenotype as a result of } \\
\text { partial functional disomy. } \\
\text { Associated in previous study with } \\
\text { ID and DFF (24) }\end{array}$ \\
\hline PM53 & $\begin{array}{l}\text { Fine and whorled } B L \\
\text { with hypo and } \\
\text { hyperpigmentation in } \\
\text { dorsum and inferior } \\
\text { limbs }\end{array}$ & ID, DFF & $\begin{array}{l}\text { PB: 46,XX, } \\
\text { del(4)(p16.1p15.3) } \\
\text { [50] } \\
\text { LS: 46,XX, } \\
\text { del(4)(p16.1p15.3) } \\
\text { [50] } \\
\text { DS: 46,XX, } \\
\text { del(4)(p16.1p15.3) } \\
\text { [50] }\end{array}$ & 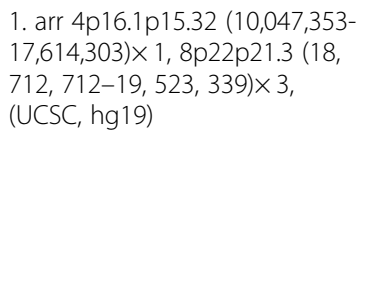 & $\begin{array}{l}\text { 1. } 0.81 \mathrm{Mb} \text { duplication including } 3 \\
\text { genes in chromosome } 8 \text { without } \\
\text { phenotype correlation } \\
\text { 2. } 7.5 \mathrm{Mb} \text { deletion including } 30 \\
\text { genes. Phenotype related: } \\
\text { a) PPP2R2C associated with ID (25) }\end{array}$ \\
\hline
\end{tabular}

MP Pigmentary Mosaicism, BL Blaschko Lines, ID Developmental Delay, DFF Dysmorphic Facial Features, M-S Musculoskeletal alterations, PB Peripheral Blood, LS

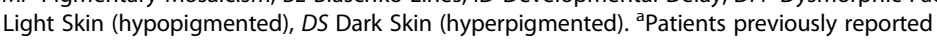

frequently involved in $\mathrm{PM}$, as in this group of patients $[3,8,13,16,18]$.

After a thorough cytogenetic analysis, the frequency of patients with chromosomal abnormalities was found to be $31 \%$, all of them with extracutaneous manifestations. In total, nineteen patients had mosaic with 2 or more cell lines with structural alterations in different tissues. Non-mosaic chromosome alteration was found in 3 patients, and polyploidy in one patient. In a previous review study, the total frequency of patients with chromosomal abnormalities was $43 \%$, with the presence of mosaic state abnormalities being the most representative [3]. In present study, the chromosomes more frequently involved in abnormalities were 12 and 22, for both numerical and structural alterations. Although there are chromosomes that are involved more frequently in abnormalities, the general spectrum of chromosomes that are found in altered karyotypes is very broad; this demonstrates the need to diagnose at genetic level patients with entities as PM of IH type, LWNH type or others [3]. Then, we consider that screening a large number of metaphases from three different tissues, increases the probability to know the etiology of PM. This strategy allows: 1 ) To detect different proportion of cells with chromosomal abnormalities; 2) To rule out if the alteration is confined only to a single tissue, and 3) To find an alteration by increasing the number of cells analyzed per every tissue. 


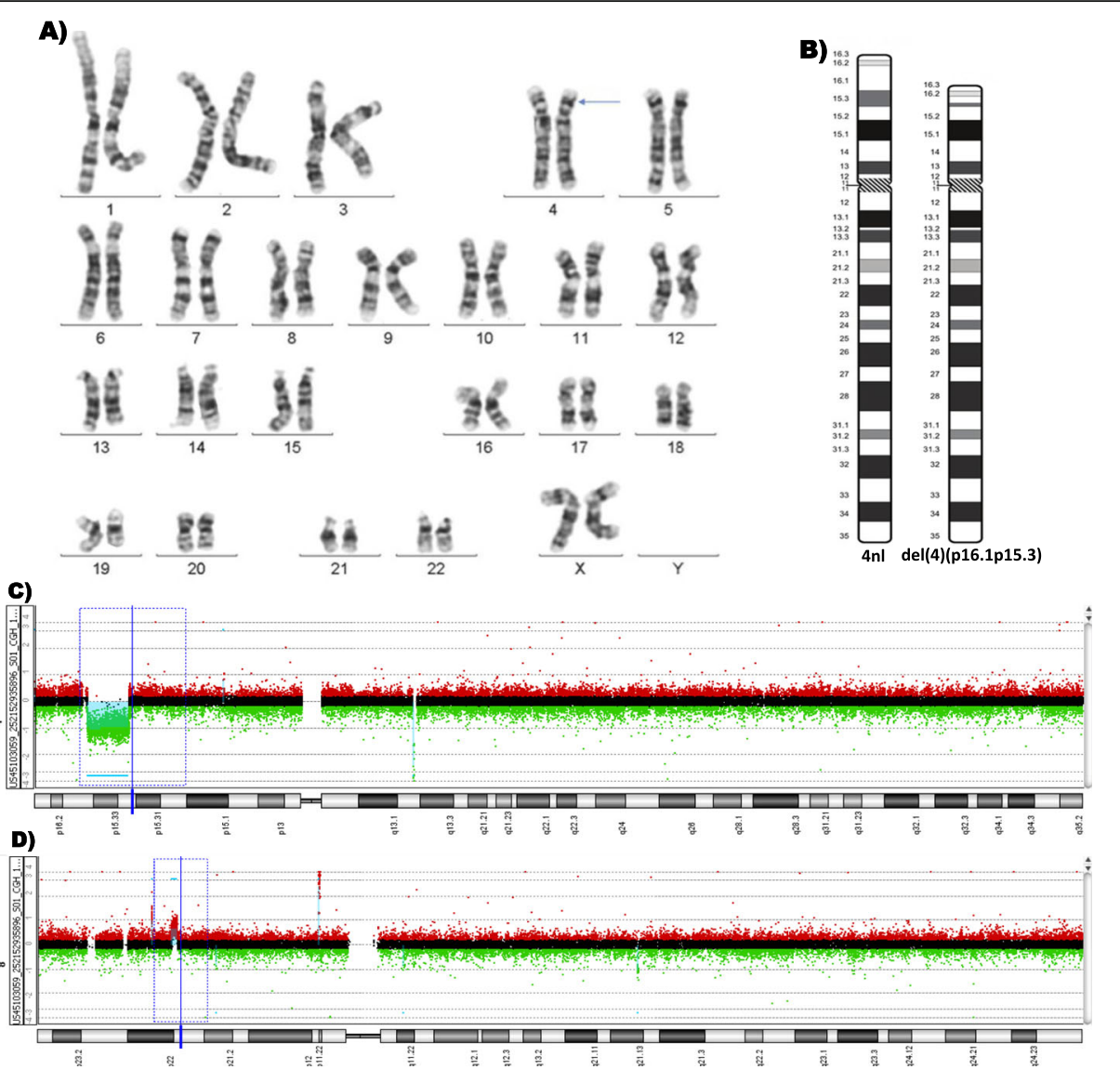

Fig. 6 Cytogenetic and molecular analysis of patient PM53. a Karyotype with del(4)(p16.1p15.3) (blue arrow); $\mathbf{b}$ Ideogram of normal (4 nl) and del(4)(p16.1p15.3) chromosomes; Microarray CGH Agilent 100 K, hg19 showing c) Deletion of 7.5 Mb in 4p16.1-p15.32 (green arrow) and d) Microduplication of $0.81 \mathrm{Mb}$ in 8p22-p21.3 (red arrow)

The presence of non-mosaic chromosomal rearrangements in 3 patients and its association with pigmentary manifestations could be explained as follow: 1) $t(X ; 22)(q 11.2 ; q 13.3)$. There is a subgroup of female patients with PM of IH type with the presence of constitutional X;autosome translocation. The phenotype in these cases results from the presence of mosaic functional disomy of $\mathrm{X}$ chromosome, as a consequence of normal $\mathrm{X}$ inactivation process during embryogenesis [3, 32]. 2) And in the other 2 patients with deletions in chromosomes 4 and 13, the chromosomal alteration itself does not explain the PM manifestations, however as described above (Table 1) could be related with some of the extracutaneous manifestations as CNS alterations [25].

An important limitation of our chromosomal analysis is the use of fibroblasts culture instead of using keratinocytes or melanocytes. However, Taibjee et al., 2009 studied patients with clinically suspected PM and normal blood cytogenetics. They analyzed fibroblasts and keratinocytes to identify chromosomal mosaicism, and the results seem to be insufficient to justify routine keratinocyte cytogenetic investigation [33]. Another option could be the analysis by SNP array or next generation sequencing (NGS) of genomic DNA directly extracted from hypopigmented and hyperpigmented skin biopsies; however, we must consider that with these molecular methodologies some of genetic abnormalities could be missed [34].

The disseminated fine and whorled BL dermatosis was present in $95 \%$ of PM patients, and considering patients with chromosomal alterations, the same pattern was presented in $78 \%$ of cases. More than 50\% of patients with extracutaneous manifestations presented more than two different systems affected. In general, the subgroup with combined pattern of pigmentation had the highest number of patients with involvement of at least three different systems. It is important to note that it seems that the more complex the pattern of distribution (disseminated) and type of pigmentation (combined pattern), the greater the number of different affected systems in the same patient and at the same time with the presence of chromosomal alterations. It has been proposed that this is a result of the presence of a greater number 
of ectodermal cells with some genetic defect associated with multiple manifestations in one patient [16]. However, related with the pigmentation pattern we cannot assume the same affirmation because only 4 patients with broad BL pattern were studied.

Accordingly to the recently described interpretation of pigmentation pattern type from an embryological point of view, PM patients were regrouped in fine and whorled $\mathrm{BL}$ pattern and in broad BL pattern, to allow a possible association with the manifestation of extracutaneous alterations [34, 35]. However in our study, and analyzing only the regrouped patients (fine and whorled BL patients group vs. broad BL patients group), no differences were observed between groups, considering skin extent of dermatosis, extracutaneous manifestations and chromosomal abnormalities associated.

Molecular analysis has also proven to be a useful tool in: 1) Detecting abnormal cell clones and 2) Completing the characterization of the chromosomal aberrations identified by classical cytogenetics. Moreover, in one patient with normal karyotype the molecular analysis detected a microdeletion in 16p11.2, this alteration has not been associated with a clearly defined phenotype but it has been reported in patients with mild intellectual disability, autism, obesity, seizures and cardiac defects. It is important to consider that the presence of other genetic changes like point mutations in genes associated with the pigmentary alterations, and some of extracutaneous manifestations, could be related with the clinical characteristics of the PM patients [3, 15, 31-33], and unfortunately could not be discarded in this study. As we demonstrated with $73 \mathrm{PM}$ patients, combining cytogenetic and molecular analysis could contribute to a better understanding of the genetic aberrations and to obtain a better genotype-phenotype correlation in this group of patients [16].

\section{Conclusion}

The search of the genetic origin of phenotypic manifestations in a heterogeneous group as PM patients, is an important challenge. PM patients with or without extracutaneous manifestations should be genetically characterized. As we showed in this study and considering the recommendations of other authors [3, 11, 27], the best strategy for the analysis of patients with pigmentary alterations is screening for chromosomal alterations in three different tissues in a large number of metaphases to discard low level mosaicism. As part of the global analysis, the application of molecular tools as microarrays or even NGS, is a necessary approach for the best genetic characterization of patients with PM. Moreover, the results obtained at the genetic level will contribute to get a better correlation with the clinical characteristics of the patient.

\section{Supplementary information}

Supplementary information accompanies this paper at https://doi.org/10. 1186/s13023-019-1208-0.

Additional file 1. "Cytogenetic alterations and molecular analysis detailed description". The detailed descriptions of the abnormal karyotypes and molecular analysis in association with phenotype in 24 patients with chromosomal abnormalities.

\section{Abbreviations \\ aCGH: array CGH; BAF: B allele frequencies; BL: Blaschko Lines; \\ CA: Chromosomal Abnormalities; CNS: Central Nervous System; del: deletion; DFF: Dysmorphic Facial Features; DS: Hyperpigmentation; FISH: Fluorescence in situ Hybridization; ID: Intellectual Disability; IH: Hypopigmentation of Ito; LS: Hypopigmentation; LWNH: Linear and Whorled Hyperpigmentation; M-S: Musculoskeletal deformities; NGS: Next Generation Sequencing; PB: Peripheral Blood Lymphocytes; PM: Pigmentary Mosaicism; UPD: Uniparental Disomy}

\section{Acknowledgements}

We are thankful to CONACYT (SALUD-2012-01-182277 and SALUD-17-01289930-01-008), Fondos Federales, Instituto Nacional de Pediatría, 2012 and Recursos Fiscales para Investigación, Instituto Nacional de Pediatría, 2017. We thank Oscar R. Castro Ayala for help with the analysis of one of the patients. We also thank all families and patients for their kind collaboration.

\section{Authors' contributions}

S-LC corresponding author, design of the study, acquisition of data, analysis and interpretation of data, drafting the article and final approval of the version to be submitted; G-CS: acquisition of clinical and analysis of data as part of a specialty in Medical Genetics; C-AR: analysis and interpretation of data; M-AD: analysis and interpretation of data as part of degree thesis; dC-RV: diagnosis and inclusion of patients, critical revision of the manuscript; D-MC: diagnosis and inclusion of patients, critical revision of the manuscript; U-AV: analysis and interpretation of data; Y-RE: diagnosis and inclusion of patients, critical revision of the manuscript; R-HA: diagnosis and inclusion of patients, critical revision of the manuscript; N-MP: analysis and interpretation of data, revised the final manuscript version; L-HE: diagnosis and inclusion of patients; G-dAA: diagnosis and inclusion of patients, critical revision of the manuscript; C-BD: diagnosis and inclusion of patients; V-CC: diagnosis and inclusion of patients, critical revision of the manuscript; R-LA: analysis of data; S-PD: acquisition of clinical data; P-MA: analysis of data; G-OA: analysis of data; P-VP: corresponding author, design of the study, acquisition of data, analysis and interpretation of data, drafting the article and final approval of the version to be submitted. All authors read and approved the final manuscript.

\section{Funding}

This work was supported by the CONACyT SALUD-17-01-289930-01-008, CONACYT SALUD-2012-01-182277 Fondos Federales, Instituto Nacional de Pediatría, 2012 and Recursos Fiscales para Investigación, Instituto Nacional de Pediatría, 2017.

\section{Availability of data and materials}

The data used and/or analysed to support the results of the current study are available from the corresponding author on reasonable request.

\section{Ethics approval and consent to participate}

This study was approved by Research Ethics committee with National Commission of Bioethics registration number "CONBIOETICA-09-CEI-02520161215" of Instituto Nacional de Pediatría. Signed informed consent form was obtained according to the recommendations of the Helsinki Declaration.

\section{Consent for publication}

Signed informed consent form was obtained according to the recommendations of the Helsinki Declaration.

Competing interests

The authors declare that they have no competing interests. 


\section{Author details}

'Laboratorio de Genética y Cáncer, Departamento de Genética Humana, Instituto Nacional de Pediatría, 04530 Ciudad de México, Mexico. ${ }^{2}$ Departamento de Genética Médica, Centro de Rehabilitación e Inclusión Infantil Teletón, Tuxtla Gutiérrez, Chiapas, Mexico. ${ }^{3}$ Departamento de Genética Humana, Instituto Nacional de Pediatría, Ciudad de México, Mexico. ${ }^{4}$ Laboratorio de Citogenética, Genos Médica, Centro Especializado en Genética, Ciudad de México, Mexico. ${ }^{5}$ Facultad de Ciencias, Universidad Nacional Autónoma de México, Ciudad de México, Mexico. ${ }^{6}$ Departamento de Dermatología, Instituto Nacional de Pediatría, Ciudad de México, Mexico. "Hospital de Especialidades Pediátrico de León, León, Guanajuato, Mexico. ${ }^{8}$ Laboratorio de Biología Molecular, Departamento de Genética Humana, Instituto Nacional de Pediatría, Ciudad de México, Mexico. ${ }^{9}$ Hospital Central Sur de Alta Especialidad, PEMEX, Ciudad de México, Mexico. ${ }^{10}$ Posgrado en Ciencias Biológicas, Universidad Nacional Autónoma de México, Ciudad de México, Mexico.

Received: 5 March 2019 Accepted: 24 September 2019

Published online: 15 November 2019

\section{References}

1. Pavone V, Signorelli SS, Praticò AD, Corsello G, Savasta S, Falsaperla R, et al. Total Hemi-overgrowth in Pigmentary Mosaicism of the (Hypomelanosis of) Ito Type: Eight Case Reports. Medicine (Baltimore). 2016;95:10.

2. Molho-Pessach V, Schaffer JV. Blaschko lines and other patterns of cutaneous mosaicism. Clin Dermatol. 2011;29:205-25.

3. Kromann AB, Ousager LB, Ali IKM, Aydemir N, Bygum A. Pigmentary mosaicism: a review of original literature and recommendations for future handling. Orphanet J Rare Dis. 2018;13:1.

4. Ruggieri M, Praticò A, Lacarrubba F, Micali G, Schepis C, Polizzi A. Archetypical patterns of skin manifestations in Neurocutaneous disorders. J Pediatr Neurol. 2018;16:255-64.

5. Happle R. Mosaicism in Human Skin [Internet]. Berlin, Heidelberg: Springer Berlin Heidelberg; 2014. p. 1-2.

6. Nehal KS. Analysis of 54 cases of hypopigmentation and hyperpigmentation along the lines of Blaschko. Arch Dermatol. 1996;132:1167.

7. Pinheiro A, Mathew MC, Thomas M, Jacob M, Srivastava VM, Cherian R, et al. The clinical profile of children in India with Pigmentary anomalies along the lines of Blaschko and central nervous system manifestations: Pigmentary anomalies along the lines of Blaschko and CNS manifestations. Pediatr Dermatol. 2007:11-7.

8. Ruggieri M, Pavone L. Topical review: Hypomelanosis of Ito: clinical syndrome or just phenotype? J Child Neurol. 2000;15:635-44.

9. Ruiz-Maldonado R, Toussaint S, Tamayo L, Laterza A, Castillo V. Hypomelanosis of Ito: diagnostic criteria and report of 41 cases. Pediatr Dermatol. 1992:9:1-10.

10. Kentab AY. The neurologic aspects of hypomelanosis of Ito: case report and review of the literature. Sudanese J Paediatrics. 2014;14:10.

11. Lombillo VA, Sybert VP. Mosaicism in cutaneous pigmentation. Curr Opin Pediatr. 2005;17:494-500

12. Loomis CA. Linear hypopigmentation and hyperpigmentation, including mosaicism. Semin Cutan Med Surg. 1997;16:44-53.

13. Küster W, König A. Hypomelanosis of Ito: no entity, but a cutaneous sign of mosaicism. Am J Med Genet. 1999:85:346-50.

14. Paller AS. Pigmentary patterning as a clinical clue of genetic mosaicism. Arch Dermatol. 1996;132:1234-5.

15. Thomas IT. Association of Pigmentary Anomalies with chromosomal and genetic Mosaicism and Chimerism. Am J Hum Genet. 1989;45:193-205.

16. Treat J. Patterned pigmentation in children. Pediatr Clin N Am. 2010; 57:1121-9.

17. Taibjee SM, Bennett DC, Moss C. Abnormal pigmentation in hypomelanosis of Ito and pigmentary mosaicism: the role of pigmentary genes. $\mathrm{Br} J$ Dermatol. 2004;151:269-82.

18. Failla P, Romano C, Schepis C. Hypomelanosis of Ito: a syndrome requiring a multisystem approach. Australas J Dermatol. 1997;38:65-70.

19. Moss C. Cytogenetic and molecular evidence for cutaneous mosaicism: the ectodermal origin of Blaschko lines. Am J Med Genet. 1999;85:330-3.

20. McGowan-Jordan J, Simons A, Schmid M. International Standing Committee on Human Cytogenomic Nomenclature. ISCN: an international system for human cytogenomic nomenclature; 2016. p. 2016.
21. Salas-Labadía C, Cervantes-Barragán DE, Cruz-Alcívar R, Daber RD, Conlin LK, Leonard LD, et al. Cytogenomic and phenotypic analysis in low-level monosomy 7 mosaicism with non-supernumerary ring chromosome 7. Am J Med Genet A. 2014;164:1765-9.

22. Conlin LK, Thiel BD, Bonnemann CG, Medne L, Ernst LM, Zackai EH, et al. Mechanisms of mosaicism, chimerism and uniparental disomy identified by single nucleotide polymorphism array analysis. Hum Mol Genet. 2010;19:1263-75.

23. Salas-Labadía C, Lieberman E, Cruz-Alcívar R, Navarrete-Meneses P, Gómez S, Cantú-Reyna C, et al. Partial and complete trisomy 14 mosaicism: clinical follow-up, cytogenetic and molecular analysis. Mol Cytogenet. 2014;7:65

24. Sheath KL, Mazzaschi RL, Aftimos S, Gregersen NE, George AM, Love DR. Clinical outcomes and Counselling issues regarding partial trisomy of terminal Xp in a child with developmental delay. Sultan Qaboos Univ Med J. 2013;13:311-7.

25. Backx L, Vermeesch J, Pijkels E, de Ravel T, Seuntjens E, Van Esch H. PPP2R2C, a gene disrupted in autosomal dominant intellectual disability. Eur J Med Genet. 2010;53:239-43.

26. Schacht JP, Farnworth E, Hogue J, Rohena L. Tetraploid-diploid mosaicism in a patient with pigmentary anomalies of hair and skin: a new dermatologic feature. Clin Case Rep. 2017;6:103-8.

27. Cohen J, Shahrokh K, Cohen B. Analysis of 36 cases of Blaschkoid dyspigmentation: reading between the lines of Blaschko. Pediatr Dermatol. 2014;31:471-6.

28. Pascual-Castroviejo I, López-Rodriguez L. Medina M de la C, SalamancaMaesso C, Herrero CR. Hypomelanosis of Ito. Neurological complications in 34 cases. Can J Neurol Sci J Can Sci Neurol. 1988;15:124-9.

29. Glover MT, Brett EM, Atherton DJ. Hypomelanosis of Ito: spectrum of the disease. J Pediatr. 1989;115:75-80.

30. Pascual-Castroviejo I, Roche C, Martinez-Bermejo A, Arcas J, Lopez-Martin V, Tendero A, et al. Hypomelanosis of ITO. A study of 76 infantile cases. Brain and Development. 1998;20:36-43.

31. Woods CG, Bankier A, Curry J, Sheffield L, Slaney SF, Smith K, et al. Asymmetry and skin pigmentary anomalies in chromosome mosaicism. J Med Genet. 1994;31:694-701.

32. Hatchwell E, Robinson D, Crolla JA, Cockwell AE. X inactivation analysis in a female with hypomelanosis of Ito associated with a balanced $X_{i} 17$ translocation: evidence for functional disomy of Xp. J Med Genet. 1996;33:216-20.

33. Taibjee SM, Hall D, Balderson D, Larkins S, Stubbs T, Moss C. Keratinocyte cytogenetics in 10 patients with pigmentary mosaicism: identification of one case of trisomy 20 mosaicism confined to keratinocytes. Clin Exp Dermatol. 2009;34:823-9.

34. Kinsler VA, Boccara O, Fraitag S, Torrelo A, Vabres P, Diociauti A. Mosaic abnormalities of the skin - review and guidelines from the European Reference Network for rare skin diseases ( ERN -Skin). Br J Dermatol. 2019. https://doi.org/10.1111/bjd.17924.

35. Kinsler VA, Larue $L$. The patterns of birthmarks suggest a novel population of melanocyte precursors arising around the time of gastrulation. Pigment Cell Melanoma Res. 2018;31:95-109.

\section{Publisher's Note}

Springer Nature remains neutral with regard to jurisdictional claims in published maps and institutional affiliations.

Ready to submit your research? Choose BMC and benefit from:

- fast, convenient online submission

- thorough peer review by experienced researchers in your field

- rapid publication on acceptance

- support for research data, including large and complex data types

- gold Open Access which fosters wider collaboration and increased citations

- maximum visibility for your research: over $100 \mathrm{M}$ website views per year

At BMC, research is always in progress.

Learn more biomedcentral.com/submissions 